\title{
Uma bebida, muitas visões: apontamentos sociológicos sobre a II Conferência Mundial da Ayahuasca
}

\section{One beverage, many "visions": sociological notes on the II World Ayahuasca Conference}

\author{
Glauber Loures Assis* \\ * Universidade Federal de Minas Gerais - Belo Horizonte, MG, Brasil \\ Em pós-doutoramento (bolsista Capes) \\ glauberloris@hotmail.com \\ Jacqueline Alves Rodrigues ${ }^{* \star}$ \\ ** Universidade Federal de Minas Gerais - Belo Horizonte, MG, Brasil \\ Mestranda em Antropologia \\ jacqueline.art@gmail.com
}




\title{
Resumo
}

Procuramos, neste artigo, trazer alguns apontamentos sobre elementos que permeiam as redes neoxamânicas contemporâneas, tais como: trânsito e deslocamento de pessoas e artefatos, tradição e autenticidade, patrimônio, tecnologias xamânicas, peregrinação e turismo religioso, intercâmbio e alianças entre grupos diversos, bem como o estabelecimento de relações de "mercado", disputas e conflitos inter-religiosos. Para tanto, elencamos como estudo de caso a II Conferência Mundial da Ayahuasca, que congregou um número sem precedentes de pessoas e grupos envolvidos com a temática da ayahuasca, como antropólogos, povos indígenas, ONGs e religiões. Pretendemos mostrar que as redes neoxamânicas contemporâneas também se constituem em meio a relações de poder, interesses conflitantes e uma multiplicidade de posicionamentos diferentes sobre cultura e religião, e que existe um verdadeiro campo ayahuasqueiro brasileiro e muitas visões distintas a respeito da ayahuasca, onde estão em jogo elementos como prestígio, legitimidade social, identidade e patrimônio.

Palavras-chave: ayahuasca; redes neoxamânicas; xamanismo; tradição.

\begin{abstract}
In this article, we seek to bring some notes about elements that permeate contemporary neoshamanic networks, such as transit and displacement of people and artifacts, tradition and authenticity, patrimony, shamanic technologies, pilgrimage and religious tourism, interchange and alliances among diverse groups, as well as the establishment of disputes, conflicts and "market" relationships, and inter-religious conflicts. In order to do so, we observe as a case study the II World Ayahuasca Conference, which brought together an unprecedented number of people and groups involved in the theme of ayahuasca, such as anthropologists, indigenous peoples and religions. We intend to show that contemporary neoshamanic networks are also constituted through relations of power, conflicting interests and a multiplicity of different views on culture and religion, and that there actually is a Brazilian ayahuasca field and many different "visions" regarding ayahuasca, where elements such as prestige, social legitimacy, identity and patrimony are in dispute.
\end{abstract}

Keywords: ayahuasca; neoshamanic networks; shamanism; tradition. 
Este artigo pretende discutir alguns aspectos das redes neoxamânicas contemporâneas, entendidas aqui, grosso modo, como a ampla circulação de pessoas, grupos e eventos que ministram e divulgam a ayahuasca e outras plantas ditas "sagradas" nos centros urbanos do Brasil e do exterior. Para tanto, focamos nossa atenção em aspectos tais como trânsito e circulação de indivíduos e artefatos, tradição e autenticidade, peregrinação e turismo religioso, intercâmbio e alianças entre grupos diversos, bem como o estabelecimento de relações de "mercado" e conflitos inter-religiosos, a partir de uma etnografia da II Conferência Mundial da Ayahuasca, realizada entre os dias 17 e 22 de outubro de 2016, em Rio Branco.

Pretendemos fazê-lo através de uma perspectiva da sociologia do conflito (Bourdieu, 1989; Weber, 1988), que não foque tão somente na descrição etnográfica ou se limite a avaliar pontos que contribuem para a coesão ou solidariedade grupal, mas privilegie o olhar também para disputas, rupturas e tensões. Com isso, pretendemos mostrar que as redes neoxamânicas contemporâneas também se constituem em meio a relações de poder, interesses conflitantes e uma multiplicidade de visões diferentes sobre cultura e religião, e que existe um verdadeiro campo ayahuasqueiro brasileiro (Assis, 2017), onde estão em jogo elementos como prestígio, legitimidade social, tecnologias xamânicas, identidade e patrimônio. ${ }^{1}$

\section{De alucinógeno a sacramento: apontamentos iniciais sobre a ayahuasca}

A ayahuasca, nome genérico de origem quéchua, língua franca de parte da floresta amazônica, que em uma tradução mais literal significa "cipó de morto" (e também é traduzido mais livre e poeticamente como "vinho das almas"),

1 Como background etnográfico deste artigo, lançamos mão de um extenso trabalho de campo que abarcou a pesquisa in loco dos autores em igrejas do Santo Daime nos estados de Minas Gerais, Rio de Janeiro, Acre e Amazonas, centros da União do Vegetal em Minas Gerais, Acre e Pernambuco, núcleos da Barquinha no Acre e rituais indígenas no estado acriano; entrevistas semiestruturadas com membros e lideranças dessas religiões e junto a representantes indígenas; entrevistas em profundidade com pesquisadores da temática da ayahuasca no Brasil; e a pesquisa etnográfica de ambos os autores na II Conferência Mundial da Ayahuasca e diversos outros eventos e seminários acadêmicos sobre o tema. 
é a bebida psicoativa utilizada ritualmente por religiões, como o Santo Daime e a União do Vegetal; povos indígenas, como os Yawanawa e os Ashaninka; e toda uma gama de pessoas que vão de vegetalistas peruanos a neoxamãs que habitam as grandes metrópoles. Essa bebida, ou tecnologia xamânica, no sentido de ser um instrumento utilizado para fins místicos e religiosos, é designada de diferentes maneiras de acordo com a cultura que a utiliza. $O$ nome que se tornou uma forma genérica e consagrada no meio acadêmico é ayahuasca, mas ela também é conhecida como yagé pelos Siona, caapi pelos Baniwa, kamarãpi entre os Ashaninka, kamalãpi junto aos Manchineri, nixi pae no meio kaxinawa, uni entre o povo yawanawa, "vegetal" ou "hoasca", entre outras denominações. Seu uso e sua origem, entretanto, extrapolam esse cenário.

Em primeiro lugar, a ayahuasca não é encontrada in natura no meio ambiente, sendo antes uma bebida preparada a partir de plantas distintas. Em contextos diferentes, diversas plantas podem fazer parte da beberagem. Entretanto, sua fórmula mais conhecida é a coç̧ão do cipó Banisteriopis caapi em conjunto com a folha Psychotria viridis. Já o efeito psicoativo produzido pela ayahuasca decorre especialmente da substância dimetiltriptamina (DMT), presente nas folhas de Psychotria viridis. O êxtase produzido pela ingestão da bebida, entretanto, só ocorre pela associação da DMT com os alcaloides presentes no Banisteriopis caapi, harmina, harmalina e tetrahidroharmina. Ou seja, os efeitos da ayahuasca só podem ser sentidos pelas pessoas por conta da união das duas plantas e seus componentes utilizados no preparo da bebida. Ou seja, o próprio efeito da ayahuasca tem um caráter "emergente" (Sawyer, 2005), sui generis, isto é: não pode ser avaliado totalmente a partir de seus componentes isolados, mas somente na simbiose e relação entre as plantas e sua interação com o corpo humano. ${ }^{2}$

Quanto aos efeitos propriamente ditos da ingestão da ayahuasca, estes podem incluir sensações de mal-estar físico, e produzir reações como vômitos e diarreias. Mas eles se dão sobretudo no nível da subjetividade humana, e podem variar bastante de acordo com o indivíduo e o contexto de utilização. Incluem sensações de euforia e bem-estar, alteração da percepção somática,

2 Para utilizar uma metáfora durkheimiana, a ayahuasca enquanto bebida é mais complexa do que a simples soma de suas partes individuais. 
modificações na percepção visual com olhos abertos, acesso a lembranças e informações biográficas subconscientes, e ainda "visões" diversas com os olhos fechados. Os aspectos visionários, as "muitas visões da ayahuasca", são, inclusive, aqueles mais lembrados e evocados por seus consumidores quando falam sobre a bebida. Ademais, tanto os efeitos físicos quanto subjetivos podem ser interpretados e vivenciados de maneiras distintas, de acordo com a pessoa que a consome e o setting onde é feito seu uso (Zinberg, 1984). O ato de vomitar pode ser interpretado desde "cura e limpeza espiritual" até simplesmente "passar mal", enquanto que os efeitos na esfera subjetiva são entendidos como desde "revelações de cunho místico" até a simples "interação neuroquímica".

Com relação à origem da bebida, há muita controvérsia. Os grupos religiosos que a utilizam vinculam seu uso a um passado mítico e longínquo, como o império inca; embora isso possa ser motivado por sentimentos genuínos de fé, é interessante notar que essa ligação a uma "tradição" e a um passado mais remoto cumpre uma importante função como ferramenta de legitimação da bebida e de quem a utiliza, já que o suposto uso tradicional vinculado a tempos imemoriais dá credibilidade frente à sociedade (Dawson, 2017). Como argumenta Beyer (2006), no sistema religioso contemporâneo a caracterização de um grupo como "tradição" cumpre um papel importante para sua legitimação social.

Além disso, essa conexão com raízes míticas e longínquas se torna um elemento distintivo na competição inter-religiosa e proeminência dentro do cenário globalizado da espiritualidade. Mesmo para além dos discursos nativos, contudo, a origem da ayahuasca permanece incerta, o que favorece a construção de narrativas míticas e contribui para dar uma aura de mistério para a bebida e para aqueles que dela fazem uso.

Já com relação à sua utilização, a ayahuasca, derivada da cocção de plantas retiradas da natureza, é consumida por diferentes povos para diferentes fins. Além disso, hoje, com a expansão da ayahuasca para os centros urbanos (Labate, 2004), há o surgimento de uma rede "neoayahuasqueira" e neoxamânica, onde a abrangência de significados e usos da bebida adquire caráter jamais visto, de modo que ela é consumida para fins terapêuticos, artísticos, religiosos e lúdicos das mais diferentes maneiras.

Assim, os usos da ayahuasca variam muito de contexto para contexto, e essa bebida só pode ser compreendida mais profundamente em seus efeitos 
e desdobramentos nos seres humanos se inserida nesses grupos sociais e sistemas simbólicos específicos. Dentre os grupos consumidores de ayahuasca mais proeminentes no campo ayahuasqueiro, encontram-se as assim chamadas "religiões ayahuasqueiras brasileiras", a saber, Santo Daime, União do Vegetal e Barquinha; diversas etnias indígenas da América do Sul; "vegetalistas" peruanos; "taitas" colombianos; dentre outros.

Nesse panorama, que também é marcado por tensões e disputas envolvendo múltiplos agentes que vão desde religiões institucionalizadas até o Estado e a política de drogas, uma ocasião sem precedentes para a observação desse campo e das diferentes visões que os grupos possuem sobre a bebida foi a II Conferência Mundial da Ayahuasca, que por essa razão funcionará como estudo de caso e objeto etnográfico de nosso artigo.

\section{A II Conferência Mundial da Ayahuasca}

Entre os dias 17 e 22 de outubro de 2016, aconteceu no campus da Universidade Federal do Acre (Ufac), em Rio Branco, a II Conferência Mundial da Ayahuasca. Foi um dos espaços de maior pluralidade ayahuasqueira que se tem notícia até os dias de hoje e um dos recortes mais significativos da complexidade do universo da ayahuasca, do campo ayahuasqueiro, ${ }^{3}$ e das redes xamânicas e neoxamânicas contemporâneas da ayahuasca. Estiveram presentes representantes de diversas etnias indígenas, religiões ayahuasqueiras, xamãs, psiconautas, ${ }^{4}$ terapeutas, sociólogos, antropólogos, cientistas de outras áreas do conhecimento, médicos, políticos, estudantes e uma multiplicidade de pessoas de várias línguas, povos e culturas de diversas partes do Brasil e do mundo.

Destinamos todo um artigo para tratar do assunto porque essa conferência de fato ilustra bem e de um modo mais amplo os dilemas, conflitos, alianças e jogos políticos envolvidos no campo ayahuasqueiro, que por sua vez dialoga

3 Nossa ideia de campo ayahuasqueiro tem como inspiração o conceito de campo de Pierre Bourdieu (1989), bem como alguns trabalhos sobre a temática da ayahuasca que já utilizam a expressão (p. ex. Assis, 2017).

4 Pessoas que utilizam substâncias psicoativas sob uma perspectiva secular, que pode incluir a busca por autoconhecimento, experiências lúdicas e recreativas, arte, dentre outras finalidades. 
com diversas esferas e se desdobra em muitos outros subcampos, influenciando também as redes xamânicas contemporâneas que dialogam com a ayahuasca e outras plantas psicoativas.

A heterogeneidade da ayahuasca, sua inerente multidisciplinaridade, sua utilização e reclamação por parte de diversas culturas e visões de mundo diferentes (e por vezes divergentes) e a entrada de novos atores nas discussões políticas que a envolvem estiveram manifestas nessa conferência, que pode servir para mapear o campo ayahuasqueiro atual e analisar a posição de cada um de seus agentes em particular, bem como apontar para alguns dos possíveis desdobramentos do universo ayahuasqueiro e da própria bebida sagrada.

Ao contrário do que ocorre no campo religioso brasileiro de um modo geral, onde, apesar da existência de uma grande variedade de profissões de fé há uma hegemonia absoluta do cristianismo e suas diferentes ramificações - sobretudo católica e pentecostal, como mostram as últimas edições do Censo (Instituto Brasileiro de Geografia e Estatística, 2012) -, no campo ayahuasqueiro há um pluralismo "de fato" e cada vez maior, isto é, uma multiplicidade de agentes que possuem relevância no quadro geral, e uma dificuldade muito grande no estabelecimento de monopólio por parte de um ou outro grupo ou religião. Em um ambiente tão multifacetado, não é de se surpreender que já tenham ocorrido outras conferências internacionais.

Assim, desde o primeiro momento o nome "II Conferência Mundial da Ayahuasca" provocou algum debate e foi justificado pelos seus organizadores. Isso porque a própria cidade de Rio Branco outrora já fora sede de um "I Seminário Internacional da Ayahuasca", e diversos outros eventos de caráter ecumênico/multicultural receberam nomes semelhantes nas últimas décadas, uma vez que essa ideia de um evento que represente a ayahuasca de forma "internacional" ou "mundial" é auferidora de legitimidade e status, algo também muito presente no circuito de religiosidade Nova Era e no neoxamanismo.

Divergências em torno do pioneirismo sobre os congressos internacionais da ayahuasca inclusive criaram animosidades entre seus organizadores. No caso da II Conferência Mundial da Ayahuasca, ou simplesmente II AyaConference, esta foi organizada pelo International Center for Ethnobotanical Education, Research \& Service (ICEERS), ONG transnacional sediada na Espanha que coloca como seus objetivos: "1) integração da ayahuasca, da iboga e de outras plantas tradicionais como ferramentas terapêuticas na sociedade ocidental, 
e 2) a preservação das culturas indígenas que utilizam estas espécies botânicas desde a antiguidade, seu habitat e recursos botânicos" (tradução nossa). ${ }^{5}$

O ICEERS já tinha sido responsável pela I Conferência Mundial da Ayahuasca, realizada na cidade de Ibiza, na Espanha. Embora tenha contado com expoentes importantes do universo ayahuasqueiro em nível internacional, especialmente da área acadêmica, relatos de campo nos deram conta de que esse evento, sediado em um conhecido balneário turístico europeu, teve dificuldades em ser visto como algo "representativo" do campo ayahuasqueiro e em estabelecer um diálogo aprofundado com os grupos nativos de um modo geral, bem como em se desvencilhar da ideia de um evento Nova Era. Resolver essa questão foi uma das razões pelas quais Rio Branco passou a ser considerada para hospedar a segunda conferência. De acordo com o pesquisador Juarez Bonfim (2016), além de Rio Branco a cidade peruana de Cuzco também era cogitada para sediar o evento.

Cuzco é um dos principais destinos do turismo espiritual da América do Sul, e daria um caráter misterioso, "exótico", "xamânico" e romantizado ao evento que certamente chamaria a atenção do público ocidental interessado na bebida sagrada. Cuzco, entretanto, não tem uma ligação histórica forte com grupos ayahuasqueiros, pelo menos não tanto quanto Rio Branco. Uma das "capitais mundiais da ayahuasca", Rio Branco é berço de duas das religiões ayahuasqueiras, Santo Daime e Barquinha, e o estado do Acre abriga as terras de mais de uma dezena de povos indígenas que utilizam essa bebida como seu sacramento, além de ter um considerável número de centros da União do Vegetal, inclusive dissidências do Centro Espírita Beneficente União do Vegetal (Cebudv) (maior representante dessa religião), e das vertentes expansionistas do Santo Daime, como Igreja do Culto Eclético da Fluente Luz Universal (Iceflu) ${ }^{6}$ e Centro Eclético Flor do Lótus Iluminado (Cefli).

A princípio, Rio Branco seria um cenário ideal para a realização de uma conferência desse tipo. Seria uma conquista imediata de legitimidade através do território (Rio Branco), mutatis mutandis semelhante a realizar

5 Cf. http://www.iceers.org/ (acesso em 20/12/2017).

6 A Iceflu é responsável direta pela expansão internacional do Santo Daime, alcançando hoje cerca de 43 países em todos os continentes habitados e contando com aproximadamente 15.000 membros ao redor do globo. 
uma conferência sobre o islã em uma das cidades sagradas dessa religião no mundo árabe, ou sobre o cristianismo primitivo em Jerusalém. Inclusive é exatamente isso que grupos evangélicos neopentecostais procuram fazer, obter legitimação perante seu público através de alguma ligação com a "Terra Santa". Não à toa, a própria Igreja Universal do Reino de Deus (Iurd) mantém igrejas funcionando em Israel, a despeito do número muito reduzido de adeptos, pelo caráter estratégico desse lugar. À parte a "magia do território", havia também um ganho real de proximidade e diálogo junto aos nativos ayahuasqueiros em relação à cidade de Ibiza, e conseguir estabelecer uma ponte com esses grupos seria um "carimbo" de legitimidade e representatividade "mundial" da conferência.

Uma primeira viagem exploratória do ICEERS a Rio Branco foi realizada, tendo à frente Juan Carlos de la Cal, daimista dirigente de um grupo ligado à Iceflu em Madri. Juan Carlos já tinha estado antes no Acre, além de conhecer o Céu do Mapiá, sede da Iceflu. De acordo com Bonfim (2016), houve reuniões e sondagens realizadas junto ao governo do Acre e assessores dos órgãos do estado, que deram sinal de apoio governamental à realização do evento em terras acrianas.

A partir dessa receptividade, um novo grupo do ICEERS visitou Rio Branco. Dessa visita resultou a escolha da terra de Chico Mendes como a sede do evento. Explicações oficiais da ONG espanhola se direcionaram especialmente no sentido de estabelecer um diálogo e ter uma maior representatividade de vozes nativas, especialmente junto aos povos indígenas consumidores da ayahuasca e aos "porta-vozes" dos mestres fundadores das religiões ayahuasqueiras. Esse diálogo, contudo, se revelou complexo e conflituoso, pelas próprias divergências e contradições internas dos grupos ayahuasqueiros acrianos, mas também pela suspeita desses atores em relação ao evento e reserva perante seus organizadores.

Para estabelecer uma ponte entre os estrangeiros do ICEERS e os brasileiros, e também para diminuir o gap entre os universos nativo, acadêmico e dos organizadores, a ONG espanhola elencou a antropóloga Beatriz Labate, uma das mais representativas e profícuas estudiosas sobre a ayahuasca em todo o mundo, que conhece muito bem o campo e tem um relacionamento - muitas vezes conflituoso - de vários anos com diversas tradições ayahuasqueiras, para compor o comitê científico do encontro. 
As conversas e negociações do comitê científico junto às comunidades ayahuasqueiras no período que precedeu o evento foram tanto intensas quanto tensas. Afinal de contas, a pretensão do congresso era nada menos do que reunir em um mesmo espaço acadêmicos, indígenas e religiosos, o que contemplava um universo muito grande e variado de grupos e pessoas que por vezes tinham uma relação muito tensionada entre si, e representavam culturas, lógicas de pensamento, epistemologias e interesses diferentes e não raro divergentes.

O evento seria organizado a partir de diversas atividades ocorridas simultaneamente. Haveria a "mesa principal", composta por convidados - dos quais boa parte obteria financiamento do ICEERS. Dentre estes, se incluíam representantes das religiões ayahuasqueiras, lideranças indígenas, políticos, xamãs, neoxamãs e pesquisadores de renome internacional, como o caso do etnobotânico Dennis McKenna. Também foi aberto um call for papers, cujos trabalhos passariam a contemplar a "mesa acadêmica", apresentada paralelamente à mesa principal, e que contou com a apresentação de pesquisas de diversas áreas do conhecimento, como sociologia, antropologia, etnomusicologia e psicologia. Além disso, haveria um espaço destinado à exibição de documentários e filmes sobre a ayahuasca, chamado de "Ayafilm". Embora louvada por uma boa parcela de ayahuasqueiros e entusiastas da bebida sagrada, a II AyaConference recebeu muitas críticas e questionamentos antes mesmo de sua realização. Uma reclamação geral era por conta do preço dos bilhetes.

A organização da conferência teria um custo de vários milhares de dólares, e para o evento se autofinanciar seria necessária a venda de ingressos como forma de arrecadação. Isso deu margem a questionamentos. Primeiramente, porque os próprios participantes do encontro - excetuando os convidados teriam que pagar pela sua participação. Ademais, todos os espectadores precisariam adquirir a entrada, mesmo o evento sendo sediado em uma universidade pública, a Ufac. O preço do ingresso também foi motivo para insatisfações, pois girava em torno de 90 euros. Ademais, a pré-venda de bilhetes esteve abaixo do esperado, o que preocupou os organizadores e os fez cogitar possibilidades alternativas de popularização do evento, como convidar figuras conhecidas das redes neoxamânicas a fazerem uma participação especial, o que no fim acabou não se concretizando.

Na véspera do início da conferência, um dos autores deste artigo esteve no Alto Santo, sede da vertente não expansionista do Santo Daime, onde 
presenciou diversas reclamações sobre a cobrança financeira para a participação no evento. A própria Madrinha Peregrina, dirigente do centro e viúva de seu fundador, Raimundo Irineu Serra, chegou a dizer que era contrária à entrada de seu grupo na conferência, pois "não ganharia nada com isso"; ao contrário, a seu ver os únicos que "ganhariam" alguma coisa seriam seus organizadores.

Após diversas conversas com alguns membros favoráveis à participação do Alto Santo, Peregrina acabou dando o seu aval para o envolvimento das pessoas de seu grupo, mas ela mesma se recusou a ir até a conferência ou apoiar publicamente a iniciativa. Esse posicionamento, longe de ser uma idiossincrasia de Peregrina Gomes Serra, parece espelhar uma opinião geral entre os ayahuasqueiros da região, especialmente os indígenas: os nativos seriam os "verdadeiros" hospedeiros, guardiões e representantes das discussões sobre a ayahuasca. Assim, não faria sentido pagar para participar de uma conferência sobre o assunto. Ainda mais uma conferência realizada por europeus.

Por parte dos indígenas, houve diversas reclamações sobre a suposta sub-representatividade deles no evento, e a falta de financiamento adequado para participar do mesmo. De lado dos organizadores, o ICEERS adotou uma política de distribuição de convites para alguns dos grupos ayahuasqueiros mais representativos de Rio Branco, e acordou um financiamento para a participação de alguns povos indígenas. Isso também deu margem para discussões, pois alguns representantes das religiões não gostaram da ideia de uma ajuda financeira concreta - e, segundo eles, "grande" - ser destinada aos indígenas, enquanto a eles por sua vez sobrariam alguns "poucos convites".

Já do lado dos indígenas, o financiamento era considerado por alguns como insuficiente, e o tratamento dado a eles como "desrespeitoso". O ICEERS procurava adotar uma postura diplomática, tentando sempre minimizar as insatisfações, sem deixar, por outro lado, de aproveitar retoricamente os símbolos nativos para a promoção do seu evento. A principal imagem de divulgação da conferência, por exemplo, era a foto de um indígena, com os dizeres em inglês: "II World Ayahuasca Conference, Rio Branco, Brazil", o que já demonstrava a pretensão universalista e a busca por "autenticidade" e pela autorrepresentação como "coisa nativa" por parte de seus organizadores.

Em suma, havia uma grande desconfiança dos nativos em relação ao ICEERS. Para usar a linguagem de Strathern (1987), eles "suspeitavam que estavam sendo explorados", isto é, que os espanhóis ganhariam prestígio às suas custas, 
e possivelmente também dólares, e queriam se apropriar daquilo que lhes pertence. Essa suspeita se intensificava na medida em que a própria identidade do ICEERS era ambígua e amorfa. Por um lado, cumpria a função de mediadora entre os atores e de organizadora da conferência; eram "acadêmicos". Por outro, também era composta por ayahuasqueiros e parte interessada na questão da bebida e sua patrimonialização, como veremos adiante; ou seja, também eram agentes políticos, "autores" (Strathern, 1987). Além disso, o nome do evento e toda a simbologia de sua divulgação evocava a ideia de uma "representatividade" internacional.

Dentro dessa postura universalista do ICEERS, havia uma tentativa de inclusão de diferentes grupos, alguns muito divergentes entre si, na realização da cerimônia. As disputas e animosidades entre esses atores tornava a tarefa de construir o cronograma do evento algo bastante complexo. Diversos grupos reclamavam por uma maior representatividade na Conferência, e por vezes uns não aceitavam dividir o espaço com outros. A União do Vegetal, por exemplo, depois de já ter negociado seu aceite ao convite, ameaçou voltar atrás e não participar do congresso. Por sua vez, as autoproclamadas "comunidades tradicionais" - Alto Santo, Cebudv e Casa de Jesus Fonte de Luz (vertente ortodoxa da Barquinha) - advogavam um espaço exclusivo destinado às "religiões", circunscrito a esses três expoentes ayahuasqueiros, excluindo assim outros grupos que também se assumiam enquanto religiões e seguidores legítimos dos mesmos mestres fundadores das três denominações em questão, como é o caso, especialmente, da Iceflu, vertente expansionista do Santo Daime.

Uma outra problemática adicional se deu por conta da natureza do evento. Afinal de contas, era um evento acadêmico ou neoxamânico e Nova Era? Isto é, seria restrito a apresentações e discussões no formato de palestras e discussões intelectuais, ou caberia também a organização de workshops, rituais de ayahuasca, pajelança indígena, comércio de artesanato e produtos relacionados à ayahuasca, terapias alternativas, etc.? A princípio, a organização do evento parecia querer restringir ao máximo a conferência a um formato acadêmico. Isso ecoava também certo posicionamento das religiões tradicionalistas, contrárias a "misturar" as esferas espiritual/religiosa e acadêmica.

Já do lado dos indígenas, essa separação não parecia fazer o menor sentido. Além de simplesmente "falar ao microfone" e "adornar o ambiente", 
os indígenas também queriam apresentar sua arte, sua cultura, sua religiosidade, seu povo. Esse entendimento também era compartilhado pelos representantes Nova Era do campo ayahuasqueiro e por grande parcela do público que estaria presente na conferência. A postura do ICEERS, a partir disso, passou a ser a de liberar uma feira de artesanatos no local do evento, e não se envolver com qualquer tipo de atividade para-acadêmica, mas também não se opor à divulgação ou realização de nenhum tipo de cerimônia ou evento paralelo por parte dos participantes da conferência.

Todas essas questões já deixavam claro, desde antes do início do congresso, algumas das suas características marcantes: os lobbies políticos de cada grupo, as divergências sobre o formato e a natureza da conferência, as disputas e necessidades em torno de financiamento, e os embates dos grupos ayahuasqueiros entre si e destes com o ICEERS. Em suma, a pluralidade e complexidade do campo ayahuasqueiro e das redes neoxamânicas da ayahuasca concentradas e reveladas em um evento.

Depois de muita negociação nos bastidores, a conferência trouxe uma programação rica e diversificada que, apesar das críticas e insatisfações, de fato apresentou um lócus dos mais representativos da história em termos de seus participantes. Participaram de alguma forma do evento: cientistas de renome internacional, como o já citado etnobotânico Dennis McKenna (irmão do "guru" psicodélico Terrence McKenna); terapeutas conhecidos no cenário ayahuasqueiro mundial, como Jacques Mabit; políticos, como o prefeito de Rio Branco, Marcus Alexandre, e o senador Jorge Viana (PT-AC); religiões ayahuasqueiras - especialmente Alto Santo (Santo Daime), Casa de Jesus Fonte de Luz (Barquinha) e Cebudv; antropólogos historicamente importantes sobre a temática da ayahuasca, como Beatriz Labate, Clodomir Monteiro, Edward MacRae e Sandra Goulart; psiquiatras, como Luís Fernando Tófoli; xamãs e vegetalistas amazônicos, como Carlos Llenera Chaves; além de representantes de 17 povos indígenas amazônicos; dentre outros.

Uma das ausências mais sentidas certamente foi a da Iceflu, que acabou não enviando representante oficial de sua diretoria, apesar de ter sido sondada pela organização da conferência. Segundo o tesoureiro da Iceflu (comunicação pessoal, 2016), uma razão fundamental da não participação teria sido o caráter discriminatório do evento em relação à instituição. Isso porque, devido aos arranjos políticos e o lobby dos grupos "tradicionalistas", a Iceflu não seria 
incluída na mesa das religiões, mas na mesa dos "ecléticos". Foi essa a saída que o ICEERS tinha arranjado para contornar a disputa no campo das religiões ayahuasqueiras. Segundo alguns relatos de campo, o Padrinho Alfredo, líder máximo dessa vertente do Santo Daime, até chegou a cogitar sua presença, mas foi aconselhado por assessores e pessoas próximas a não participar, pois o evento representaria uma exposição desnecessária perante diversos de seus principais antagonistas, como o Alto Santo e Cebudv.

Além disso, o porta-voz natural da Iceflu em eventos desse tipo, Alex Polari, se encontrava viajando ao exterior e não poderia comparecer. Os maiores temores por parte dos representantes dessa denominação religiosa diziam respeito a dois pontos: a) a utilização ritual de Cannabis sativa no âmbito desse grupo, sob o nome de "Santa Maria" (MacRae, 2005), encarada pelos tradicionalistas como uso ilegítimo de drogas e perversão da tradição; b) o processo diaspórico da Iceflu, traduzido por seus opositores como "comercialização" do Santo Daime. Enfim, o julgamento da direção da Iceflu era que a correlação de forças entre seus simpatizantes e o Alto Santo, Cebudv e Casa de Jesus Fonte de Luz estava desequilibrada em benefício dos últimos, que tinham a seu favor, dentre outros elementos, boas relações e alianças políticas na cidade e no estado do Acre.

Alto Santo e Casa de Jesus Fonte de Luz, inclusive, eram sediados e nascidos em Rio Branco. A ausência de representantes oficiais da Iceflu foi uma grande frustração por parte de boa parte do público. Algumas pessoas inclusive esperavam que o clímax da conferência pudesse ser o encontro "frente a frente" de representantes da Iceflu e dos grupos tradicionalistas.

Ao que tudo indica, porém, a radiografia do evento feita pela Iceflu subestimou sua própria força e a complexidade da conferência. Isso porque ali havia dezenas de membros e "simpatizantes" dessa denominação religiosa, não só como espectadores mas também como palestrantes, especialmente na "mesa acadêmica", além de diversos dirigentes de igrejas ligadas ao grupo, entre outros. O fator principal não avaliado pelos representantes do Céu do Mapiá, contudo, foram os povos indígenas, que representaram um contraponto muito forte em relação aos assim chamados grupos tradicionalistas. Uma possível aliança política de algumas etnias indígenas com a Iceflu, com a qual diversos representantes indígenas presentes no evento têm algum tipo de relação, poderia representar uma verdadeira ameaça ao poderio dos grupos tradicionalistas sobre os caminhos tomados pela conferência. 
Do lado das religiões tradicionalistas, críticas veladas foram endereçadas à Iceflu, com acusações diversas de "uso de drogas" e "comércio de daime" feitas por representantes dos grupos tradicionalistas, especialmente nas falas de membros do Alto Santo. Em relação a esses posicionamentos, eles encontraram alguma resistência por parte da plateia, que fez intervenções questionando, por exemplo, a "perseguição à Cannabis", inclusive uma curiosa intervenção de um daimista presente na plateia que deu um "viva a ganja!" e fez questão de cantar um "ponto de preto velho" para saudar a diversidade religiosa e o uso de Santa Maria, e outras intervenções ao longo do evento.

\section{Início da conferência, protagonismo indígena e explosão de conflitos}

Voltando à organização do evento, este contou com tradução simultânea de suas mesas principais para inglês, português e espanhol. As mesas de caráter científico e acadêmico foram compostas pelo ICEERS, enquanto as mesas indígenas e as mesas das "religiões" tiveram sua composição a cargo de seus próprios representantes. Isto é, foram os próprios grupos nativos que escolheram os participantes dessas discussões. As mesas indígenas e "das religiões" representaram, por certo, alguns dos pontos altos do evento, e dialogaram bastante entre si. A bem da verdade, o fiel da balança de toda a conferência talvez tenha sido a participação dos indígenas, que historicamente tiveram um papel muito pequeno nas discussões acadêmicas sobre a ayahuasca e foram pouquíssimo representados nos debates sobre legalização, expansão e patrimonialização da bebida sagrada (Assis, 2017; Labate; Coutinho, 2014).

Interessante notar que, justamente no evento acadêmico/social sobre ayahuasca da civilização ocidental com a maior representação indígena da história, houve uma das maiores, mais firmes e mais amplas manifestações de protesto dos indígenas em torno da abordagem da ayahuasca. Os conflitos aí envolvidos possuem diversas razões, desde questões sociais mais amplas até contingências e fatos ocorridos na própria conferência.

Historicamente, os indígenas sempre foram evocados retoricamente nas narrativas de religiões ayahuasqueiras, neoayahuasqueiros e neoxamãs para legitimar as práticas desses grupos. Todos eles, de uma forma ou outra, 
procuravam ligar sua prática religiosa a "tradições imemoriais" da ayahuasca, se apresentando de alguma maneira como continuadores da religiosidade ancestral ameríndia. Houve, com isso, por parte desses grupos, uma folclorização do indígena e sua relação com a bebida, isto é, seu tratamento como parte de um imaginário cultural mítico, e não como um agente real, com suas próprias demandas, presente na sociedade contemporânea. Acontece que há diversos povos indígenas que ainda hoje fazem uso da ayahuasca e têm se tornado conhecidos de um público mais amplo. Nos últimos anos, vem ocorrendo uma inserção cada vez maior de indígenas no circuito ayahuasqueiro e nas redes neoxamânicas das grandes cidades brasileiras e do exterior.

Esse movimento já foi observado por trabalhos como os de Labate e Coutinho (2014) e Rose (2010). Envolve muitos elementos, não só um "empoderamento" e maior protagonismo indígena no cenário ayahuasqueiro Nova Era e neoxamânico, mas também possíveis relações de exploração da religiosidade indígena por parte de ocidentais, e de todo modo uma intensa rede de relações entre indígenas e brancos, que passa inevitavelmente pelo intermédio de "facilitadores" e "atravessadores" não indígenas, que oferecem workshops e cerimônias com lideranças indígenas para o público urbano e algumas vezes influenciam bastante na inserção dos indígenas nas redes de religiosidade Nova Era.

Essa busca por autenticidade indígena no cenário contemporâneo faz com que muitas vezes indígenas jovens e não iniciados sejam recrutados pelos "empreendedores" religiosos da ayahuasca, que os apresentam como "grandes xamãs". Algumas vezes os indígenas que saem das aldeias para realizar "cerimônias" nesses modelos são altamente criticados e desacreditados enquanto xamãs dentro de seu próprio povo.

Um pouco da complexidade da emergência indígena no universo ayahuasqueiro foi ilustrada na presença de diversas etnias na conferência. Alguns dias antes da realização do evento, foi divulgado um cronograma de cerimônias indígenas com ayahuasca a serem realizadas durante a noite em todos os dias da semana. Cada dia seria destinado a uma etnia, e a última cerimônia integraria todas as etnias envolvidas com a organização desses rituais. Esse movimento era construído pelos indígenas em parceria com ONGs e pessoas do Sudeste que "empresariam" a realização dessas cerimônias pelo Brasil e pelo mundo. Tais cerimônias teriam um custo financeiro variado. Tomar parte 
em rodas de rapé teria um custo aproximado de $\mathrm{R} \$ 60,00$, enquanto a participação nos rituais de ayahuasca chegaria a $\mathrm{R} \$ 200,00$ por sessão.

Essa questão financeira era ambígua, na medida em que no primeiro dia da conferência alguns representantes indígenas transpareciam em suas falas ideias de tradição, pureza, sacralidade e legitimidade que não tocavam na dimensão monetária da ayahuasca. Tanto é que um dos momentos mais significativos do primeiro dia de discussões foi quando um rapaz, em sua intervenção, perguntou a um representante indígena sobre o preço para participar das cerimônias. Em seu raciocínio, não questionava exatamente o direito dos indígenas de cobrarem pelos rituais, mas clamava pela possibilidade de participação daqueles que, "como ele", não pudessem pagar. Houve um silêncio no auditório e nenhum indígena respondeu claramente à questão.

Tudo isso entrou em choque com o posicionamento de Alto Santo, Cebudv e Casa de Jesus Fonte de Luz, fortemente contrárias a qualquer tipo de "comercialização" da bebida, um discurso construído ao longo dos anos especialmente por conta de sua identidade contrastiva (Cardoso de Oliveira, 1976) em relação à Iceflu e seu movimento de expansão e "alianças" religiosas diversas. Acontece que os povos indígenas não operam nos mesmos parâmetros da Iceflu, nem são percebidos da mesma maneira pelo público. Assim, a mesma lógica de comercialização aplicada nas acusações contra a Iceflu não tem o mesmo efeito e a mesma recepção quando direcionada aos indígenas. Foi essa discrepância que caracterizou um dos momentos fundamentais da conferência, a fala de Cosmo Lima de Souza, representante do Alto Santo e procurador de Justiça do estado do Acre.

Originalmente escalado para falar sobre como Mestre Irineu, fundador do Santo Daime, conquistou legitimidade para seu grupo através dos tempos, Cosmo sustentou que haveria uma "legitimidade inerente" ao Alto Santo e demais religiões tradicionalistas. Segundo ele, quem traz a ilegitimidade e 0 questionamento acerca das práticas religiosas ayahuasqueiras são os grupos "desviantes" e as práticas que denigrem essa "legitimidade natural" que a ayahuasca teria. Esse argumento inicial serviu de gancho para que Cosmo direcionasse a maior parte de sua fala a tecer duras críticas à utilização de outras substâncias juntamente com a ayahuasca e à "comercialização" da bebida. Muito contundente em suas declarações, disse ainda que não haveria a menor possibilidade da construção de um documento em conjunto 
pelos participantes da conferência, uma proposta inicial do ICEERS, caso continuasse a ocorrer a mercantilização da ayahuasca durante o evento.

Com essa fala, ele se referia às já citadas cerimônias indígenas, que estavam sendo informalmente divulgadas por alguns de seus porta-vozes não indígenas entre o público da conferência. Cosmo ainda foi além, cobrando publicamente um posicionamento do ICEERS em relação a esses rituais e também dos porta-vozes indígenas, chegando a citar publicamente Benki Piyãko, liderança ashaninka, e pedindo explicações públicas sobre essa questão, com o argumento de que isso não combinava com a sacralidade da ayahuasca. Esse foi um grande momento de inflexão da II AyaConference, que desvelou e tornou públicos os conflitos e disputas políticas que até então aconteciam nos bastidores.

Óscar Parés, um dos organizadores do evento, tomou a palavra e fez uma nota de esclarecimento, segundo a qual o ICEERS não estava envolvido na realização de nenhuma cerimônia religiosa, nem tampouco era contra ou poderia proibir a livre articulação dos grupos ayahuasqueiros em relação à organização de rituais. Benki também falou, evocando a ancestralidade do uso indígena da ayahuasca, sem polemizar nem expor um posicionamento mais categórico sobre a questão. Coube ao público o maior contraponto à fala de Cosmo. Uma das pessoas que pediram a palavra, em discurso apaixonado, sustentava que "tudo" havia sido tirado dos indígenas, e agora que existe algo de sua cultura que é valorizado pelos ocidentais, a ayahuasca, "como os brancos podem ousar querer tirar deles o direito de usufruir das possibilidades que se abrem com isso?"

Esse ponto escancarou os conflitos e divergências de ideias até então mantidos sob um véu de diplomacia, e também produziu resultados práticos. Um deles foi uma maior flexibilização das cerimônias indígenas com ayahuasca realizadas em Rio Branco durante o evento. Os preços passaram a ter uma margem maior de negociação, e caíram consideravelmente. Em relação à percepção do público, as posições também passaram a ser mais marcadas. Adeptos do Alto Santo e das religiões tradicionalistas louvavam a fala de Cosmo como a "melhor" até aquele momento, enquanto indigenistas - pessoas atuantes na política de integração e proteção das populações indígenas - passavam a recrudescer sua opinião crítica ao evento.

Dali por diante, se tornou possível identificar com clareza as preferências do público dentro desse campo ayahuasqueiro. Antes semelhante a uma massa amorfa, doravante o público passava a se assemelhar a uma "torcida de futebol", 
que aplaudia e se entusiasmava com o porta-voz de seus interesses mais imediatos, e se contrariava com posicionamentos, narrativas e valores contrários aos de seus representantes. Essa configuração, longe de ser um aspecto negativo da conferência, foi reveladora da pluralidade ayahuasqueira e ajudou a politizar a discussão. Essa forte polarização do debate, aliás, foi uma característica emergente (Sawyer, 2005) da conferência que certamente extrapolou as ideias iniciais de seus organizadores.

Reunir em um mesmo local tantos grupos diferentes e muitas vezes detentores de posicionamentos opostos, com variadas culturas e epistemologias, teve como um de seus efeitos mais pronunciados, além de uma real diversidade, a politização, que deu a tônica em vários momentos, desde o início. Já a primeira mesa indígena, de apresentação de seus representantes, foi composta por mais de uma dezena de pessoas. Recordemos que foram os próprios indígenas os responsáveis pela composição dessa mesa. Ali já começaram as queixas por conta do espaço exíguo e do tempo insuficiente para sua participação. Esse posicionamento era ecoado por indigenistas, e contraposto pelos entusiastas da conferência, por exemplo, da seguinte maneira: "Se eles quisessem mais tempo, deveriam compor a mesa com três ou quatro pessoas, como todas as outras meses, e não com mais de uma dezena! Ademais, temos que respeitar os horários das outras mesas; é impossível postergar indefinidamente uma discussão."

Já nessa primeira roda de discussões, conflitos internos aos próprios indígenas também apareceram. As duas mulheres que compuseram a mesa foram as últimas a falar, queixando-se disso se expressando publicamente com palavras como "até que enfim!". A questão de gênero no mundo indígena da ayahuasca é catalisada especialmente na figura de Putanny e Hushahu Yawanawa, duas irmãs que se tornaram as primeiras "pajés da ayahuasca" de que temos notícia entre os indígenas do Acre.

Historicamente, a ayahuasca é um privilégio masculino nas aldeias, especialmente em relação às posições de direção das cerimônias. Essas duas mulheres representaram uma verdadeira quebra de paradigma, ao se tornarem pajés reconhecidas por suas etnias como tais, o que aconteceu em 2006, não sem diversas manifestações de oposição. Elas contam como passaram por intensas provações antes dessa conquista, tendo que ir além daquilo que os homens pediam a elas em sua iniciação, para "provar" sua força. Foi assim que ambas 
conseguiram esse direito através do pajé Tata, uma das maiores e mais antigas lideranças yawanawa, falecido no final de 2016 com mais de 100 anos de idade.

O caso de Putanny e Hushahu inclusive ativou um movimento mais amplo, onde outras mulheres de outras etnias também passaram a ministrar a ayahuasca e ter acesso aos conhecimentos sobre a bebida outrora de caráter exclusivamente masculino. Esse foi o caso entre os Ashaninka e os Katukina, por exemplo. Dentre as cerimônias indígenas realizadas em Rio Branco durante a conferência, houve uma liderada por essas duas mulheres. Apesar dessa transformação em direção a uma maior agência feminina na questão da ayahuasca, a participação das mulheres nas cerimônias ainda gera muita controvérsia no meio indígena. Vários veteranos e anciãos, por exemplo, consideram essa "inovação" ilegítima, configurando um campo de lutas sobre o papel das mulheres no universo ayahuasqueiro indígena que merece ser observado. Trabalhos sobre a questão da mulher indígena em relação à ayahuasca ainda são muito escassos, e uma das áreas mais interessantes de pesquisa, pois representa mudanças significativas na questão de gênero no interior desse universo.

Como dissemos, depois do posicionamento de Cosmo Lima de Souza, houve uma polarização mais escancarada. De um lado, as religiões ayahuasqueiras tradicionalistas, muito influentes em Rio Branco, e todo o séquito de seus seguidores; de outro lado, as etnias indígenas e vários de seus simpatizantes, dentre os quais muitos adeptos da Iceflu. Em meio a esse conflito, acadêmicos se tornaram "simples acadêmicos", isto é, em boa medida deixaram o palco principal e o protagonismo da conferência, e o ICEERS passou a ser visto cada vez mais como uma "entidade estrangeira", o que, se não deixa de ser verdade, por outro lado motivou críticas mordazes por parte de uma parcela do público.

Um posicionamento ilustrativo da difícil posição do ICEERS foi o comentário do historiador Marcos Vinícius, registrado em um blog indigenista (cf. Maia, 2016): "Quinhentos e dezesseis anos depois estamos nós aqui reunidos com Igrejas, Europeus (em sua maioria espanhóis), e índios!” Essa imagem, que remonta ao início da violenta colonização brasileira por europeus, foi usada pelos críticos da conferência. Alguns consideravam o evento uma forma de "neocolonialismo", "etnocentrismo", "imposição cultural", chamando-o inclusive de "evento mundial de coisa nenhuma" e de "perigosa e falsa iniciativa 
"científica"' pelos seus críticos mais ferozes, em artigos presentes em blogs que se espalharam pela internet.

A diferença nas "epistemologias" dos presentes talvez tenha sido um dos pontos que determinaram as diversas críticas em relação ao formato e tempo das palestras. Por parte das religiões e dos indígenas, muitas vezes foi demonstrada uma insatisfação em relação ao caráter "academicista" do evento. Um representante da Casa de Jesus Fonte de Luz, após estourar seu tempo de fala de 20 minutos, se queixou publicamente de "boicote" às religiões e censura, solicitando que os grupos nativos pudessem falar "livremente", pelo tempo que achassem conveniente. Como o cronograma de atividades era muito intenso e dinâmico, as mesas precisavam encerrar suas discussões no horário definido, para que as atividades seguintes pudessem acontecer. Por conta disso, o espaço aberto para intervenções do público após as palestras foi pequeno, o que motivou severas críticas por parte de alguns palestrantes, que acusavam o ICEERS de querer "silenciar" e cercear as pessoas.

Houve problemas em relação a isso, pois mais de um membro da plateia se revoltou ao ter sua intervenção cortada pelos organizadores por conta do tempo. Dentre esses, havia uma suspeita de "complô" da organização do evento contra os nativos. Indígenas também foram críticos constantes do formato da conferência por razões semelhantes. Seus defensores acusavam a organização de "arrogância intelectual" e "elitismo". Do lado do ICEERS, não havia muito o que fazer, a não ser seguir com a programação, arrefecendo os ânimos o máximo possível. Mais do que implicâncias de cunho pessoal, talvez esses conflitos demonstrem epistemologias e interpretações de mundo diferentes.

Para o ICEERS, a conferência era sobretudo "científica", e os nativos eram participantes e convidados, mas não os condutores principais. Para religiões e indígenas, ser "enquadrado" no formato proposto pela organização era ter seu protagonismo e relevância usurpados por uma instituição estrangeira. No caso das religiões, poderia representar uma "afronta", como demonstrado pela fala da representação da Casa de Jesus Fonte de Luz. Para os indígenas, ficava a impressão de que mais uma vez os ocidentais pretendiam tratá-los como inferiores e sem consideração. O fato é que, como vimos, a posição do ICEERS era indefinida, o que motivava essa multiplicidade de visões a seu respeito. 


\section{A reunião sobre a patrimonialização e dificuldades no posicionamento coletivo das entidades ayahuasqueiras}

A maior mostra dessa discrepância de pensamentos talvez tenha sido a reunião sobre patrimonialização da ayahuasca, que aconteceu a portas fechadas somente para convidados durante o evento. A ideia de patrimonialização da bebida foi evocada no Brasil especialmente a partir das religiões ayahuasqueiras, como forma de "proteção" do uso religioso da ayahuasca e de uma mudança de esferas no tratamento dado pelo Estado à questão, isto é, no intuito de a ayahuasca ser vista como algo da esfera da cultura, e não da justiça. Tratava-se de pleitear junto ao governo o reconhecimento da ayahuasca como patrimônio cultural do Brasil, em moldes semelhantes ao que houve no Peru, onde a patrimonialização cultural da ayahuasca já é uma realidade (Goulart; Labate, 2016).

Ocorre que, no caso brasileiro, essa demanda deixou de lado em um primeiro momento importantes atores do campo ayahuasqueiro, especialmente a Iceflu e os povos indígenas. Com o avançar das discussões, o Instituto do Patrimônio Histórico e Artístico Nacional (Iphan) passou a incluir esses grupos no processo de patrimonialização, e isso aprofundou e complexificou muito a discussão, uma vez que novos interesses e visões sobre o tema emergiram. No âmbito internacional, ONGs como o ICEERS também passaram a se preocupar com o movimento de patrimonialização da ayahuasca em seus próprios termos, qual seja, a ideia de a bebida ser considerada um patrimônio imaterial da humanidade.

Essa multiplicidade de visões e interesses por vezes divergentes tornou a reunião sobre a patrimonialização um dos momentos cruciais da conferência. Segundo o relato de alguns dos participantes, houve um conflito aberto de posicionamentos na ocasião. Antropólogos versus indígenas, indígenas versus igrejas, igrejas versus antropólogos, igrejas versus igrejas, todos versus ICEERS, enfim, foram várias as combinações possíveis de contendas que se materializaram na ocasião. Houve indígenas que desafiaram os demais presentes a "curar" com a ayahuasca, segundo uma concepção de que são os povos originários os únicos e "verdadeiros" detentores do saber ayahuasqueiro. Em resposta, um antropólogo-ayahuasqueiro fez um discurso apaixonado reivindicando a sua própria legitimidade enquanto alguém que de alguma forma também 
representaria a bebida. Pelo lado das religiões, o posicionamento continuava batendo na mesma tecla: contrário a qualquer tipo de comercialização e "mistura" de outras substâncias ao ritual da ayahuasca e em direção a um "legalismo" ayahuasqueiro. Já do lado do ICEERS, havia o pleito do reconhecimento da ayahuasca como patrimônio da humanidade.

Essas discussões levantam as seguintes e importantes questões: de quem é a ayahuasca, e quem pode decidir sobre sua utilização? Uma provocação interessante foi feita em uma das falas acadêmicas da conferência, segundo a qual a "ayahuasca é muito importante para ser deixada na mão dos psiquiatras". Nesse caso, ela deveria ser colocada nas mãos de quem? Esse quadro que esboçamos serve para mostrar em alguma medida que tipo de conflito e interesse político está envolvido na questão da patrimonialização.

Trata-se, em última instância, de definir quem são os agentes legítimos para se pronunciar sobre a bebida. Em comum, ayahuasqueiros presentes na reunião de modo geral concordam que o uso ayahuasca é um assunto que deve ser tratado especialmente no âmbito da cultura. Mas as visões sobre isso são muito distintas. O título de uma matéria escrita por um representante do ICEERS no blog oficial da conferência (Bouso, 2016) espelha bem o posicionamento dessa instituição. O texto é intitulado "El poder está en la ayahuasca... no en quien la da" (“O poder está na ayahuasca, não em quem a dá"). Em outros termos, pode-se apreender daí que a ayahuasca poderia ser tratada de modo dissociado dos contextos onde é utilizada, o que fortalece a tese de que é um patrimônio não territorializável e que não pertence a nenhum grupo, ou seja, não tem caráter étnico, se constituindo assim como um "patrimônio da humanidade".

De fato, essa era uma das maiores bandeiras históricas do ICEERS, que remonta ao ano de 2011. Nesse período, o International Narcotic Control Board (INCB), das Nações Unidas, publicou um relatório anual fazendo menção à ayahuasca e sustentando um posicionamento que sinalizava o apoio para algumas políticas proibicionistas. Em contraposição a esse posicionamento é que começa a haver a articulação do ICEERS em favor do reconhecimento da ayahuasca e suas práticas como patrimônio imaterial da humanidade.

A reunião sobre patrimonialização ocorrida na conferência foi uma ideia do ICEERS na direção desses seus planos de nível internacional, isto é, debater estratégias para dar andamento ao processo de reconhecimento da ayahuasca e práticas associadas como patrimônio da humanidade. Para tanto, a reunião 
foi organizada a partir de pelo menos seis meses de negociações, e contou com mais de 20 convidados, dentre antropólogos, especialistas na discussão de patrimônio, tradutores e representantes dos diversos grupos ayahuasqueiros presentes no evento. Uma das premissas do ICEERS é que a ayahuasca está na direção de se tornar algo mainstream na sociedade ocidental, cada vez mais inserida nos círculos de religiosidade alternativa e neoxamânicos, e atraindo cada vez mais pessoas em busca do "novo" e do "misterioso", inclusive celebridades de Hollywood e empreendedores do Silicon Valley.

Nesse ambiente expansionista, há também muitos casos complicados e graves relacionados ao turismo religioso, como o abuso de mulheres, a falta de segurança e credibilidade de algumas cerimônias, etc. Nesse sentido, ONGs como o ICEERS argumentam que é mais importante do que nunca criar mecanismos de salvaguardar e regular o uso da ayahuasca no mundo globalizado, como é o caso da patrimonialização.

Acontece que o posicionamento universalista do ICEERS não obteve a adesão imaginada junto aos grupos ayahuasqueiros. Para estes, a ayahuasca não era algo dissociado dos contextos culturais e sociais de seu uso. Aliás, para muitos deles nem sequer fazia sentido falar em "ayahuasca" como se fosse uma única bebida, genérica. Foi assim que alguns indígenas se expressaram em suas falas durante o evento. As etnias que mais ou menos diretamente participaram da conferência foram as seguintes: yawanawa, shanenawa, jaminawa, huni kuĩ, apurinã, manchinery, katukina, nukini, puyanawa, ashaninka, madja, jamamadi, nawa, shawãdawa, apolima-arara, jaminawa-arara e kuntanawa, que correspondem a três troncos linguísticos distintos: pano, aruak e arawa. Há diversos nomes diferentes entre si pelos quais esses povos compreendem a bebida sagrada genericamente chamada de ayahuasca pela comunidade científica, como uni, para os Yawanawa, nixi pae, para os Huni Kuĩ, ou kamarãpi, para os Ashaninka.

Para muitos desses povos indígenas, o que eles tomam não é a mesma coisa que se convencionou chamar de ayahuasca. Em um relato de campo colhido durante a conferência, um pajé ayahuasqueiro afirmava: "Eu não sei o que é ayahuasca." Isso porque, para ele, a bebida que seu povo comungava era outra, nixi pae. Isso revela como os contextos culturais determinam fortemente a ideia que se tem sobre o chá. Bebida e cultura não poderiam ser vistas de forma isolada. 
Sendo assim, não seria somente a partir dos princípios ativos em comum que se poderia classificar a planta sagrada; igualmente importante seriam o ambiente e a forma pela qual ela é utilizada. Isso significa dotar a ayahuasca de um caráter étnico, algo que de certa forma era compartilhado pelas religiões ayahuasqueiras tradicionalistas, com a diferença de que neste último caso havia a tendência à construção de uma narrativa monopolista e exclusivista sobre o consumo do daime/vegetal/ayahuasca, e um desejo de classificação entre usos sagrados e profanos e legítimos e ilegítimos que de certa forma passava ao largo dos questionamentos indígenas, mais ligados ao reconhecimento de sua cultura e seu povo e menos à proibição-restrição do uso em relação aos outros.

Esse caráter étnico do qual a bebida era dotada dificultou a união em torno da proposta do ICEERS sobre a patrimonialização em âmbito internacional. As diferenças de posicionamentos entre religiões, indígenas e antropólogos/ cientistas também inviabilizou a confluência dos interesses em torno de uma proposta em comum sobre a questão em âmbito nacional. Havia uma forte desconfiança por parte de indígenas em relação ao movimento pela patrimonialização. Houve quem acusasse alguns intermediários de "influenciar e contaminar as lideranças indígenas contra uma futura e benéfica patrimonialização", como é o caso de alguns artigos presentes em blogs e jornais na internet (Bonfim, 2016).

Por outro lado, alguns indigenistas acusaram os estrangeiros de "apropriação cultural", de querer patrimonializar algo que "nada tem a ver com eles". Outra reclamação foi de que o movimento de regulamentação da ayahuasca até então protegeu mais as religiões do que os indígenas. Como exemplo, alguns chegaram a citar a grande dificuldade que indígenas têm de transportar sua "garrafinha de cipó" em aviões, segundo eles muito maior do que aquela enfrentada por membros de religiões como o Santo Daime.

Interessante lembrar aqui que, embora todos os atores presentes na conferência evocassem a ideia do poder da bebida em si mesma, a própria discussão sobre a patrimonialização contém de alguma forma a ideia de propriedade. Isso significaria dizer que a ayahuasca de certa forma pertence a alguém, seja este alguém povos indígenas, religiões, psiconautas, acadêmicos ou a "humanidade". Acontece que, segundo várias interpretações nativas, a bebida sagrada é, ela mesma, um ator, ou um actante (Latour, 2012). 
Aprofundando esse raciocínio, os grupos que fazem uso ritual da ayahuasca de um modo geral a consideram um "ser", uma entidade dotada de consciência e "vontade" próprias. Dennis Mckenna, por exemplo, sustentou que a ayahuasca é uma espécie de "emissária do resto do planeta", enquanto alguns indígenas procuraram inverter a relação de propriedade em relação à bebida, onde "não é a ayahuasca que é nossa, mas nós é que somos da ayahuasca”. É assim que temos um quadro mais amplo, onde agentes "não humanos" também influenciariam nos acontecimentos e na ação social das pessoas.

Com todos esses dilemas, não houve uma solução consensual ou deliberação unânime tirada nessa reunião, que espelhou uma vez mais os intensos conflitos presentes no campo ayahuasqueiro. Mas não foi só isso. Além de mostrar as disputas desse campo, a conferência também demonstrou sua complexidade, e ainda a emergência de diversos atores que têm se tornado relevantes nas redes neoxamânicas da ayahuasca e vêm construindo um verdadeiro pluralismo no campo ayahuasqueiro, com agentes variados em posição semelhante de poder, algo muito diferente, por exemplo, da relação totalmente assimétrica entre as religiões no campo religioso brasileiro mais amplo.

A maior "revelação" do evento nesse sentido foi demonstrar aquilo que autores como Rose (2010) e Labate e Coutinho (2014) já apontavam, isto é, a entrada dos indígenas no circuito religioso da ayahuasca, entrada essa que, ao que tudo indica, é cada vez mais crescente e autorreflexiva; ou seja, os indígenas estão se integrando cada vez mais não só no circuito de religiosidade alternativa da ayahuasca, mas também nas questões que envolvem os aspectos legais e discussões mais amplas sobre a bebida na sociedade contemporânea, reivindicando direitos e se contrapondo a posicionamentos que não contemplam seus interesses.

Essa crescente visibilidade indígena, aliada também à disseminação internacional da ayahuasca em diversas formas de utilização, como o uso científico e terapêutico e sua inserção em workshops e "rodas xamânicas de medicina" juntamente com outras substâncias de origem indígena como rapé, kambô e sananga, questiona a autorrepresentação e o poder das religiões ayahuasqueiras sobre o tema.

Muito embora os grupos tradicionalistas continuem fortes nesse campo, tenham articulado alianças entre si e diálogos diversos com o Estado e sejam atores fortíssimos nas questões jurídicas que envolvem a bebida, são cada vez mais questionados em sua pretensão de "tradicionalismo", a partir de diversas frentes. 
Um sinal de que esses questionamentos começam a surtir efeito está na própria mudança da autoidentificação do Alto Santo, Cebudv e Casa de Jesus Fonte de Luz durante a conferência. No início do evento, esses grupos se autorrepresentavam como comunidades "tradicionais" da ayahuasca. Ao final da conferência, seus discursos faziam referência a centros "tradicionalistas", evitando a palavra "tradicional", fortemente debatida e contestada nessa autodesignação.

O terapeuta francês Jacques Mabit, por exemplo, questionou ironicamente em sua fala essa ideia que as religiões fazem de si mesmas como "tradicionais". Segundo ele, a Coca-Cola é mais antiga do que a mais antiga das religiões ayahuasqueiras. Seria, portanto, necessário relativizar essa ideia de tradição. Um indígena que tomou a palavra também fez esse questionamento em outros termos, ainda mais "hereges" do ponto de vista das religiões. Segundo ele, esses "mestres" das religiões que aí estão "começaram agora" no mundo da ayahuasca, enquanto os povos indígenas já consagram a bebida a "milhares de anos". Alguns indígenas chegaram inclusive a afirmar que seu povo faz esse uso há "milhões" de anos. Essa fala, embora equivocada do ponto de vista histórico, ilustra como os indígenas estão conscientes da força da "ancestralidade" na questão da legitimação do consumo da ayahuasca.

Da parte dos acadêmicos e antropólogos, a conferência também representou um momento único, de "confronto" e discussão horizontal junto aos seus objetos de análise e grupos pesquisados. Isso rendeu situações interessantes, como por exemplo a réplica de uma representante da Casa de Jesus Fonte de Luz à fala de uma antropóloga que estudou essa denominação a partir de uma naturalização do nome Barquinha, termo que não é adotado pelo grupo em questão e que dá uma ideia de homogeneidade dentro da tradição religiosa de Mestre Daniel. Em sua intervenção, a porta-voz da entidade religiosa em questão criticou fortemente a homogeneização dos grupos e o descaso com as autorrepresentações nativas perpetradas pela antropologia, bem como a ausência de pesquisa de campo e diálogo com os representantes religiosos.

Cabe dizer também que, com todos os conflitos e disputas, a conferência foi um ambiente incrivelmente plural, e movimentou uma "cena" ayahuasqueira na cidade de Rio Branco de maneira jamais vista anteriormente. Em uma semana, a cidade foi palco de diversas cerimônias indígenas, rituais na Barquinha, trabalhos de Santo Daime no Cefli, Alto Santo e na Colônia Cinco Mil, sessões extras na União do Vegetal, experimentações psiconáuticas, 
cerimônias xamânicas, entre outros acontecimentos. Esses rituais tinham um caráter marcadamente cosmopolita, e alguns quebraram recordes de número de pessoas, como o trabalho dos Chamados realizado no Luzeiro da Manhã, filial do Cefli localizada no município do Bujari.

A conferência transformou o campus da Ufac em um microcosmo da ayahuasca. Indígenas enfeitados, pessoas tomando rapé, aplicando kambô, realizando massagens e terapias, comendo fast-food, vendendo artesanato, membros das religiões, psiconautas, uma diversidade muito grande de indivíduos que traduziu a complexidade desse universo. $O$ evento também foi palco para reconciliações, e fez com que diversos grupos que não se relacionam entre si tivessem que se encarar mutuamente e dialogar de alguma maneira.

Ao final da conferência, as religiões ayahuasqueiras acabaram adotando uma autorrepresentação mais "leve", em um claro sinal de que as diversas críticas recebidas de alguma forma também impactaram esses grupos. Como dissemos, as religiões passaram a se colocar como "tradicionalistas", em detrimento do termo "tradicionais". Foi a partir dessa identidade que Alto Santo, Casa de Jesus Fonte de Luz e Cebudv escreveram sua carta aberta sobre a conferencia. Por sua vez, os povos indígenas também escreveram sua própria carta aberta.

Esse movimento de cartas abertas frustrou a expectativa inicial dos organizadores do evento, que pretendiam unificar a opinião dos grupos ayahuasqueiros dentro de uma "declaratória" que representasse a todos. No caso da carta dos povos indígenas, ela foi marcada por diversas polêmicas. Inicialmente, os indígenas escreveram um comunicado com críticas muito fortes e contundentes ao evento. Após diversas negociações nos bastidores, foram convencidos a escrever uma versão mais "amena" e diplomática, que acabou se tornando a oficial.

Como se vê, a II Conferência Mundial da Ayahuasca produziu um efeito significativo nos grupos ayahuasqueiros. Fez eclodir diversos conflitos internos, mas também impulsionou agenciamentos e auto-organização por parte dos atores. Alguns dizem, algo ironicamente, que jamais houve uma reunião dentre tantas lideranças indígenas das etnias ayahuasqueiras como nesse evento, que por sinal motivou a realização de outros encontros indígenas para discutir em seus próprios termos algumas das questões colocadas pela conferência, como foi o caso da $1^{\text {a }}$ Conferência Indígena da Ayahuasca, ou $1^{\text {a }}$ Yubaka Hairá, que aconteceu durante a edição final deste artigo, entre os dias 14 e 17 de dezembro de 2017 na terra Puyanawa em Mâncio Lima (AC). 


\section{Considerações finais}

Procuramos, neste artigo, trazer alguns apontamentos sobre elementos que permeiam as redes neoxamânicas contemporâneas, como o trânsito e deslocamento de pessoas e artefatos; tradição e autenticidade; patrimônio; tecnologias xamânicas; peregrinação e turismo religioso; intercâmbio e alianças entre grupos diversos; além de abordar o estabelecimento de relações de "mercado" e conflitos inter-religiosos dentro desse campo. Para tanto, elencamos como estudo de caso a II Conferência Mundial da Ayahuasca, que congregou um número inédito de pessoas e grupos envolvidos com a temática da ayahuasca, como antropólogos, ONGs, povos indígenas e religiões.

Observamos que a conferência visibilizou as controvérsias e abriu a caixa-preta (Latour, 2012) do uso da ayahuasca, proporcionando assim um lócus sem precedentes para analisar as conexões sociais e fronteiras estabelecidas nesse universo, e os diferentes interesses e representações em jogo, inclusive dos próprios cientistas sociais, colocando em cheque identidades e visões constituídas, e abrindo novos fronts de batalha.

De certo modo, pensamos que esse evento faz uma excelente radiografia do campo ayahuasqueiro, apesar de algumas limitações, apontando também para certos desdobramentos contemporâneos que possivelmente vão continuar no futuro próximo: emergência dos indígenas como atores importantes no circuito urbano internacional da ayahuasca e nas redes neoxamânicas contemporâneas; estabelecimento de relações de mercado e parcerias de viagens entre ocidentais e indígenas; fortalecimento de alianças entre os centros religiosos "tradicionalistas"; crescente utilização terapêutica da ayahuasca; aumento do interesse das áreas médicas sobre o tema; inserção de instituições estrangeiras no debate sobre a ayahuasca; proliferação do uso da bebida a partir de motivos e contextos não religiosos; crescente comercialização da ayahuasca.

Seja como for, observamos que a ayahuasca é polifônica, polissêmica e policêntrica. Que o universo social da ayahuasca é permeado de alianças e conflitos internos. E que a ayahuasca é uma bebida de muitas visões, não só aquelas produzidas na subjetividade humana como efeito de sua ingestão, mas também as que são resultantes de epistemologias distintas, das formas variadas de se compreender o psicoativo (como um sacramento, como uma ferramenta xamânica ou como um alucinógeno, por exemplo), de intensas 
disputas de poder, e ainda das sensíveis diferenças culturais entre seus consumidores, que formam um campo ayahuasqueiro cada vez mais complexo, plural e efervescente.

\section{Referências}

ASSIS, G. L. A Religião of the Floresta: apontamentos sociológicos em direção a uma genealogia do Santo Daime e seu processo de diáspora. 2017. Tese (Doutorado em Sociologia)-Faculdade de Filosofia e Ciências Humanas, Universidade Federal de Minas Gerais, Belo Horizonte, 2017.

BEYER, P. Religions in global society. New York: Routledge, 2006.

BONFIM, J. D. Festa ayahuasqueira no Acre. AYA2016. II Conferência Mundial da Ayahuasca. Jornal Grande Bahia, 6 nov. 2016. Disponível em: <http://www.jornalgrandebahia.com.br/2016/11/festa-ayahuasqueira-no-acre-aya2016-ii-conferencia-mundial-da-ayahuasca/>. Acesso em: 20 dez. 2017.

BOURDIEU, P. O poder simbólico. Rio de Janeiro: Bertrand Brasil, 1989.

BOUSO, J. C. Día 6: el poder está en la ayahuasca... no en quien la da. 2016. Disponível em: <http://www.ayaconference.com/index.php/el-poder-esta-en-la-ayahuasca-no-en-quien-la-da/>. Acesso em: 20 dez. 2017.

CARDOSO DE OLIVEIRA, R. Identidade étnica, identificação e manipulação. In: CARDOSO DE OLIVEIRA, R. Identidade, etnia e estrutura social. São Paulo: Pioneira, 1976. p. 1-31.

DAWSON, A. If tradition did not exist, it would have to be invented: retraditionalization and the world ayahuasca diaspora. In: LABATE, B. et al. (Ed.). The world ayahuasca diaspora. New York: Routledge, 2017. p. 19-38.

GOULART, S.; LABATE, B. Religião, política e cultura: o uso da ayahuasca como patrimônio cultural. In: REUNIÃO BRASILEIRA DE ANTROPOLOGIA, 30., 2016, João Pessoa. Anais... Brasília: ABA, 2016. Disponível em: <http://www.abant.org.br/conteudo/ANAIS/30rba/admin/files/1467332507_ARQUIVO_ABAArtigo2016PATRIMONIOAYAHUASCASANDRAEBIAartigomaiscompleto.pdf>. Acesso em: 20 maio 2017.

INSTITUTO BRASILEIRO DE GEOGRAFIA E ESTATÍSTICA. Censo Brasileiro de 2010. Rio de Janeiro, 2012.

LABATE, B. A reinvenção do uso da ayahuasca nos centros urbanos. Campinas: Mercado de Letras, 2004. 
LABATE, B.; COUTINHO, T. "O meu avô deu a ayahuasca para o mestre Irineu”: reflexões sobre a entrada dos índios no circuito urbano de consumo de ayahuasca no Brasil. Revista de Antropologia, São Paulo, v. 57, n 2, p. 215-250, 2014.

LATOUR, B. Reagregando o social: uma introdução a teoria do ator-rede. Salvador: Edufba; Bauru: Edusc, 2012.

MacRAE, E. Santo Daime e Santa Maria: usos religiosos de plantas psicoativas lícitas e ilícitas. In: LABATE, B.; GOULART, S. (Org.). O uso ritual das plantas de poder. Campinas: Mercado de Letras, 2005. p. 459-489.

MAIA, D. Conferência da Ayahuasca: um outro olhar.... Crônicas Indigenistas, 26 out. 2016. Disponível em: <http://cronicasindigenistas.blogspot.com/2016/10/conferencia-da-ayahuasca-um-outro-olhar_25.html>. Acesso em: 20 dez. 2017.

ROSE, I. S. Tata endy rekoe - fogo sagrado: encontros entre os Guarani, a ayahuasca e o Caminho Vermelho. 2010. Tese (Doutorado em Antropologia Social)-Centro de Filosofia e Ciências Humanas, Universidade Federal de Santa Catarina, Florianópolis, 2010.

SAWYER, K. Social emergence: societies as complex systems. New York: Cambridge University Press, 2005.

STRATHERN, M. The limits of auto-anthropology. In: JACKSON, A. (Ed.). Anthropology at home. London: Tavistock, 1987. p. 16-37.

WEBER, M. Economia e sociedade: vol. 1. Brasília: EdUNB, 1988.

ZINBERG, N. Drug, set, and setting: the basis for controlled intoxicant use. New Haven: Yale University Press, 1984.

Recebido: 31/05/2017 Aceito: 14/03/2018 | Received:5/31/2017 Accepted: 3/14/2018 